\title{
Immune-related adverse events of immune checkpoint inhibitors: a brief review
}

\author{
G. Myers BScPharm ACPR*
}

\begin{abstract}
Immune checkpoint inhibitors (ICIS) such as inhibitors of CTLA-4, PD-1, and PD-L1, given as monotherapy or combination therapy have emerged as effective treatment options for immune-sensitive solid tumours and hematologic malignancies. The benefits of IcIs can be offset by immune-related adverse events (irAEs) that leave all organ systems vulnerable and subsequently increase the risk for morbidity and mortality.

Because of fluctuating onset and prolonged duration, the toxicities associated with iraes represent a shift from the understanding of conventional anticancer toxicities. The CTLA-4 and PD-1/PD-L1 inhibitors modulate T-cell response differently, resulting in distinct toxicity patterns, toxicity kinetics, and dose-toxicity relationships. Using individualized patient education, screening, and assessment for the early identification of iraes is key to proactive management and is therefore key to improving outcomes and prolonging therapy.

Management of irAEs is guided by appropriate grading, which sets the stage for the treatment setting (outpatient vs. inpatient), ICI treatment course (delay vs. discontinuation), supportive care, corticosteroid use, organ specialist consultation, and additional immunosuppression. Health care professionals in oncology must work collaboratively with emergency and community colleagues to facilitate an understanding of iraEs in an effort to optimize seamless care.
\end{abstract}

Key Words Immune-related adverse events, immune checkpoint inhibitors, toxicity, corticosteroids, immunosuppression

\section{INTRODUCTION}

The use of monoclonal antibody-based immune checkpoint inhibitors (ICIS) such as the inhibitors of CTLA-4, PD-1, and PD-L1 to manipulate the T-cell response to immunosensitive tumours has revolutionized cancer treatment ${ }^{1}$. In addition to conventional radiation, chemotherapy, and targeted anticancer therapy, ICI monotherapy and combination therapy are rapidly becoming effective options for treating solid tumours and hematologic malignancies in many settings ${ }^{2-4}$. However, the advantageous clinical outcomes associated with IcIs can be offset by potentially severe immune-related adverse events (irAEs) that are pathophysiologically unique compared with the familiar toxicities of conventional anticancer therapies. For that reason, awareness and understanding of the characteristics of irAes by all oncology team members and the general medical community are essential for optimizing patient care $^{2,5}$. This brief review addresses the major clinical considerations involved in identifying, assessing, and managing the irAEs of ICIS.

\section{GENERAL TOXICITY CONSIDERATIONS}

The pharmacodynamic and pharmacokinetic differences of ICIs compared with chemotherapy or targeted therapy result in delayed onset and prolonged duration of toxicity ${ }^{5}$. The iraEs from ICIs are hypothesized to occur in a number of ways secondary to disruption of immunologic selftolerance, and the toxicity mechanisms can vary depending on the class of $\mathrm{ICI}^{6,7}$. When comparing ICI classes, it is important to understand not only that inhibitors of CTLA-4 and of PD-1/PD-Ll differ in their toxicity mechanisms, but that their respective pharmacologic functions lead to distinct toxicity patterns ${ }^{7,8}$.

This series is brought to you in partnership with the Canadian Association of General Practitioners in Oncology.

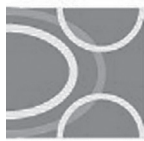


Generally speaking, rates of toxicity are higher with CTLA-4 inhibitors than with PD-1/PD-L1 inhibitors because of their "global" activation of naïve and memory T cells from the lymph nodes. In contrast, PD-1/PD-L1 inhibitors modulate T-cell activity "locally" in the peripheral tissues (for example, tumour cells or inflammatory tissue) ${ }^{8}$. Keeping in mind that iraes can affect any organ system (Table I), the specific toxicities more likely to occur with CTLA-4 inhibitors are colitis, rash, pruritus, and hypophysitis; pneumonitis, dysthyroidism, arthralgia, myalgia, and vitiligo are more likely to occur with PD-1/PD-L1 inhibitors, ${ }^{73,14}$.

Risk factors for iraEs are poorly elucidated at this time, but might include such elements as combination ICIs (for example, combined anti-CTLA-4 and anti-PD-1/PD-L1), variances in microbial gut flora (in the case of ipilimumabinduced colitis), or a personal history of autoimmune disorders, with recent evidence suggesting a higher risk of disease flares rather than de novo irAEs ${ }^{7,15-17}$. Timing of toxicity emergence is more predictable with ipilimumab because its iraEs usually occur within the 12-week induction period. In contrast, the median time to PD-1/PD-L1 irAEs can vary in the range of $1-6$ months, and the toxicity type can depend on the particular PD-1/PD-L1 inhibitor and tumour site $8,13,18,19$. Timing of ICI toxicity should be interpreted cautiously because iraEs can occur late in the treatment course or months to years after treatment discontinuation, highlighting the importance of ongoing monitoring ${ }^{2,5}$. Ipilimumab has also been shown to have a dose-dependent relationship with iraEs, as seen with the $3 \mathrm{mg} / \mathrm{kg}$ and $10 \mathrm{mg} / \mathrm{kg}$ doses (grade 3/4: $17 \%$ and $31 \%$ respectively), with evidence suggesting a lesser or inconsistent dose-dependent relationship for the PD-1/ PD-L1 inhibitors ${ }^{8,20}$.

\section{ASSESSMENT AND MANAGEMENT APPROACHES}

Identification, assessment, and management of iraes should take a proactive approach, identifying iraes early for appropriate immunosuppressant therapy and supportive care, with the goals of minimizing morbidity, preventing life-threatening complications, and continuing ICI therapy ${ }^{2,5}$. Individual patient work-ups at baseline, throughout treatment, and after discontinuation, with a thorough assessment of laboratory values, radiographic imaging, and clinical symptoms can aid in early detection (Table II) ${ }^{5}$.

A thorough baseline work-up for patients on ICIs is required because new symptoms can arise from causes such as malignancy progression, fortuitous events related to the cancer or existing medical conditions (for example, infection, thrombosis, exacerbation of chronic obstructive pulmonary disease, and so on), and iraEs ${ }^{2}$. Patients might also experience more disease-related symptoms (for example, pain or hypercalcemia) early in their treatment because of the onset with IcIs being slower than that with conventional therapies, highlighting the importance of early supportive care. Guidelines, supported by expert opinion and clinical experience, act as a valuable resource for clinicians in helping to streamline iraE management and to reduce complications of ICI therapy $y^{5,9,10,22}$.

Physicians, nurses, pharmacists, and other oncology team members who care for patients receiving ICIs must work collaboratively to provide individualized patient education, screening, and ongoing follow-up. The five pillars of immunotherapy toxicity management outlined in Champiat et al. ${ }^{2}$ can act as a foundation for establishing collaborative practice.

TABLE I Presentation of immune-related adverse events by organ system ${ }^{5,9-12}$

\begin{tabular}{|c|c|c|}
\hline \multirow[t]{2}{*}{ Organ system } & \multicolumn{2}{|r|}{ Presentation } \\
\hline & Routinely reported events & Rare or infrequently reported events \\
\hline Dermatologic & $\begin{array}{l}\text { Rash (maculopapular, lichenoid), } \\
\text { pruritus, vitiligo }\end{array}$ & $\begin{array}{c}\text { Acneiform rash, alopecia, bullous pemphigoid, papulopustular rosacea, } \\
\text { psoriasis, Stevens-Johnson syndrome, toxic epidermal necrosis, } \\
\text { DRESS, Sweet syndrome }\end{array}$ \\
\hline Gastrointestinal & Diarrhea, colitis, lichenoid mucositis & Enteritis, gastritis, pancreatitis \\
\hline Endocrine & $\begin{array}{l}\text { Hypothyroidism, hyperthyroidism, } \\
\text { thyroiditis, hypophysitis }\end{array}$ & Autoimmune type 1 diabetes, primary adrenal insufficiency \\
\hline Hepatic & Transaminitis, hepatitis & - \\
\hline Respiratory & Pneumonitis & Pleuritis, sarcoidosis \\
\hline Rheumatic & Arthralgia, inflammatory arthritis, myalgia & $\begin{array}{c}\text { Dermatomyositis, myositis, polymyalgia-like syndrome, } \\
\text { Sjögren syndrome, vasculitis }\end{array}$ \\
\hline Renal & Increase in serum creatinine, nephritis & - \\
\hline Ophthalmic & - & Uveitis, conjunctivitis, scleritis, episcleritis, blepharitis, retinitis \\
\hline Neurologic & Sensorimotor neuropathy & $\begin{array}{l}\text { Aseptic meningitis, autonomic neuropathy, encephalitis, } \\
\text { facial nerve palsy, Guillain-Barré syndrome, myasthenia gravis, } \\
\text { posterior reversible leukoencephalopathy, transverse myelitis }\end{array}$ \\
\hline Hematologic & - & $\begin{array}{l}\text { Aplastic anemia, hemolytic anemia, } \\
\text { idiopathic thrombocytopenia purpura, lymphopenia, hemophilia }\end{array}$ \\
\hline Cardiac & - & Cardiomyopathy, myocarditis, pericarditis \\
\hline
\end{tabular}

DRESS $=$ drug rash with eosinophilia and systemic symptoms. 
TABLE II Monitoring for patients taking immune checkpoint inhibitors ${ }^{2,5,9,21}$

\begin{tabular}{|c|c|c|c|}
\hline \multirow[t]{2}{*}{ Organ system } & \multicolumn{2}{|l|}{ Baseline and routine } & \multirow[t]{2}{*}{ As clinically indicated } \\
\hline & Laboratory & Other & \\
\hline Dermatologic & - & - & - \\
\hline Gastrointestinal & - & - & $\begin{array}{c}\text { Stool culture: } \\
\text { Clostridium difficile, ova and parasites, } \\
\text { bacteria, CMV DNA PCR } \\
\text { Stool calprotectin } \\
\text { Lipase with or without amylase }\end{array}$ \\
\hline Endocrine & $\begin{array}{l}\mathrm{TSH}^{\mathrm{b}} \text {, random glucose, } \\
\text { morning cortisol, }{ }^{\mathrm{c}} \text { lytes } \\
\text { Vital signs } \\
\text { Weight }\end{array}$ & - & $\begin{array}{l}\text { ACTH, TSH, thyroxine (T4 } \pm \mathrm{T} 3 \text { ), TPOAb, } \\
\text { thyroglobulin, morning cortisol, glucose, } \\
\text { luteinizing hormone, } \\
\text { follicle stimulating hormone, } \\
\text { testosterone, estrogen, growth hormone } \\
\text { Brain MRI with pituitary cuts }\end{array}$ \\
\hline Hepatic & AST, ALT, total bilirubin & - & $\begin{array}{l}\text { AST, ALT, total bilirubin, INR, albumin } \\
\text { CMV antibodies, }{ }^{\text {a }} \text { Epstein-Barr virus }{ }^{\text {a }}\end{array}$ \\
\hline Respiratory & $\begin{array}{l}\quad \mathrm{O}_{2} \text { saturation } \\
\text { (at rest and with ambulation) }\end{array}$ & $\mathrm{CT}$ chest, abdomen, pelvis ${ }^{\mathrm{d}}$ & $\begin{array}{l}\text { CT chest } \\
\text { Chest radiography }\end{array}$ \\
\hline Rheumatic & CRPe & - & $\begin{array}{c}\text { Rheumatoid factor, ANA titer, CRP, anti-CCP, } \\
\text { ESR, creatinine kinase }\end{array}$ \\
\hline Renal & Serum creatinine, lytes & - & $\begin{array}{c}\text { Serum creatinine, lytes } \\
\text { Urinalysis }\end{array}$ \\
\hline Ophthalmic & - & - & - \\
\hline Neurologic & - & - & $\begin{array}{l}\text { Lumbar puncture with analysis } \\
\text { MRI brain with or without spinal cord }\end{array}$ \\
\hline Hematologic & CBC and differential, platelets & - & CBC and differential, platelets \\
\hline Cardiovascular & - & $\mathrm{ECG}^{\mathrm{e}}$ & $\begin{array}{l}\text { ECG, echocardiogram } \\
\text { Creatinine kinase, troponin, } \\
\text { brain natriuretic peptide }\end{array}$ \\
\hline Other $^{f}$ & $\begin{array}{c}\text { Hepatitis B screening ( } \mathrm{HBsAg}, \mathrm{HBs} A b, \mathrm{HBcAb}) \\
\text { Hepatitis C antibody } \\
\text { Tuberculosis test }\end{array}$ & - & - \\
\hline
\end{tabular}

a In high-risk patients (for example, bone-marrow transplant, HIV, immunocompromised state).

b Frequency varies with institution and clinical judgment.

c Consider routine monitoring for ipilimumab or combination (CTLA-4 and PD-1/PD-L1).

d Baseline assessment of malignancy.

e Baseline for reference.

f Baseline testing in case of need for anti-tumour necrosis factor $\alpha$ (for example, infliximab).

$\mathrm{CMV}=$ cytomegalovirus; $\mathrm{PCR}=$ polymerase chain reaction; $\mathrm{TSH}=$ thyroid stimulating hormone; $\mathrm{ACTH}=$ adrenocorticotropic hormone; $\mathrm{TPOAb}=$ thyroid peroxidase antibody; $\mathrm{MRI}=$ magnetic resonance imaging; $\mathrm{AST}=$ aspartate aminotransferase; $\mathrm{ALT}=$ alanine aminotransferase; INR = international normalized ratio; $\mathrm{CT}=$ computed tomography; $\mathrm{CRP}=\mathrm{C}$-reactive protein; $\mathrm{ANA}=$ antinuclear antibodies; $\mathrm{CCP}=$ cyclic citrullinated peptide; $\mathrm{ESR}=$ erythrocyte sedimentation rate; $\mathrm{CBC}=$ complete blood count; $\mathrm{ECG}=$ electrocardiography; $\mathrm{HBsAg}, \mathrm{sAb}, \mathrm{cAb}=$ hepatitis $\mathrm{B}$ surface antigen, antibody to surface antigen, core antibody.

Once toxicity is diagnosed, appropriate irae grading can help to guide appropriate management. However, iraEs can be challenging to grade using the current Common Terminology Criteria for Adverse Events, because the criteria have limitations with respect to underestimating or overestimating the severity of irAEs and can be difficult to apply in some organ-specific iraes (for example, dermatologic, rheumatic) $)^{5,23-25}$. Table III outlines general irAE management considerations by Common Terminology Criteria for Adverse Events grade. More-detailed information about assessment and management of specific toxicities can be found in international or provincial guidelines-such as those from Cancer Care Ontario $5,9,10,26$.

\section{Dermatologic irAEs}

Skin toxicities are the most common and earliest-onset iraEs, consisting mainly of rash, vitiligo, and pruritus ${ }^{9,11}$. With all IcIs, maculopapular rash predominates. Lichenoid rashes occur with PD-1/PD-L1 inhibitors and can affect the skin as well as the oral mucosa ${ }^{27}$. Pruritus presents with or without rash and significantly compromises health-related quality of life for patients because of its resistance to traditional antipruritic therapy ${ }^{9,27}$.

Low-grade toxicity (grade 1 or 2) usually requires moderate- to high-potency topical corticosteroids and supportive care. Systemic corticosteroids and treatment delay would be warranted for grade 3 events, any 
TABLE III Management algorithm for immune-related adverse events by grade ${ }^{2,5}$

\begin{tabular}{|c|c|}
\hline Event type & Management considerations \\
\hline Grade 1 & $\begin{array}{l}\text { Asymptomatic, minimally symptomatic, or radiographic or laboratory change } \\
\text { Supportive care or localized therapy (or both) as outpatient } \\
\text { Immune checkpoint inhibitor continued } \\
\text { Increased monitoring }\end{array}$ \\
\hline Grade 2 & $\begin{array}{l}\text { Mild-to-moderate or persistent symptoms } \\
\text { Delay immune checkpoint inhibitor if corticosteroids are required } \\
\text { Oral corticosteroids }\left(0.5-1 \mathrm{mg} / \mathrm{kg}^{\mathrm{b}} \text { and supportive care as outpatient }\right. \\
\text { Pneumocystis jiroveci prophylaxis per institutional guideline and clinical judgment if } 20 \mathrm{mg} \text { or more prednisone daily for more than } \\
1 \text { month; calcium and vitamin D; and prophylaxis for lower gastrointestinal bleed if risk factors are present } \\
\text { Taper corticosteroids over at least } 2-4 \text { weeks when event reaches grade } 1 \text { or less } \\
\text { Increased monitoring; treat as grade } 3 \text { if symptoms persist }\end{array}$ \\
\hline Grade 3 & $\begin{array}{l}\text { Moderate-to-severe symptoms } \\
\text { Delay immune checkpoint inhibitor; discontinue if risk exceeds benefit } \\
\text { Oral corticosteroids }\left(1-2 \mathrm{mg} / \mathrm{kg}^{\mathrm{b}} \text { as outpatient; consider intravenous route and hospitalization if symptoms persist for } 48-72 \text { hours, }\right. \\
\text { with or without additional immunosuppressionc if no response to intravenous corticosteroids in } 48-72 \text { hours } \\
\text { Pneumocystis jiroveci prophylaxis per institutional guideline and clinical judgment if } 20 \mathrm{mg} \text { or more prednisone daily for more than } \\
1 \text { month; calcium and vitamin D; and prophylaxis for lower gastrointestinal bleed if risk factors are present } \\
\text { Taper corticosteroids over at least } 4-6 \text { weeks when event reaches grade } 1 \text { or less } \\
\text { Consider organ specialist consultation }\end{array}$ \\
\hline Grade 4 & $\begin{array}{l}\text { Life-threatening symptoms } \\
\text { Hospitalization for intravenous corticosteroids }\left(2-4 \mathrm{mg} / \mathrm{kg}^{\mathrm{b}} \text {, with or without additional immunosuppression }{ }^{\mathrm{c}} \text { if no response to }\right. \\
\text { intravenous corticosteroids in } 48-72 \text { hours } \\
\text { Pneumocystis jiroveci prophylaxis per institutional guideline and clinical judgment if } 20 \mathrm{mg} \text { or more prednisone daily for more than } \\
1 \text { month; calcium and vitamin D; and prophylaxis for lower gastrointestinal bleed if risk factors are present } \\
\text { Taper corticosteroids over at least } 4-8 \text { weeks when event reaches grade } 1 \text { or less } \\
\text { Consult with organ specialist } \\
\text { Discontinue immune checkpoint inhibitor }\end{array}$ \\
\hline
\end{tabular}

grade of blistering rash, rash with mucosal involvement, or life-threatening cutaneous reactions (for example, Stevens-Johnson Syndrome, toxic epidermal necrolysis, drug rash with eosinophilia and systemic symptoms) $)^{5,9,10,27}$.

\section{Gastrointestinal irAEs}

Diarrhea and colitis account for most gastrointestinal toxicity and appear to be a class effect with CTLA-4 inhibitors used alone or combined with PD-1/PD-L1 inhibitors ${ }^{5,10,11}$.

After infection is ruled out, isolated grade 1 diarrhea can be managed with anti-motility agents (loperamide, for instance) for 48-72 hours per guidelines; however, patients must be monitored closely during that time ${ }^{5,9,10}$. Low-dose systemic corticosteroids (for example, prednisone $10 \mathrm{mg}$ or less daily) or local budesonide are options for low-grade diarrhea if anti-motility agents are not appropriate ${ }^{9,10}$. Persistent diarrhea of any grade or colitis symptoms (abdominal pain, cramping, rectal bleeding, mucus in the stool, fever, or nausea or vomiting) should prompt immediate assessment and treatment with corticosteroids, with consideration of additional immunosuppression (for example, with infliximab) if no response to corticosteroids is observed, ${ }^{9,10,28}$.

\section{Endocrine irAEs}

Endocrine irAEs are complex, in that they can affect any axis of the endocrine system, including the pituitary, thyroid, adrenals, and pancreas ${ }^{29}$. Hypophysitis occurs mainly with CTLA-4 inhibitors or combination ICIs; dysthyroidism is predominant with PD-1/PD-L1 inhibitors.

Laboratory monitoring of endocrine function is helpful for diagnosis because symptoms are usually nonspecific, making early identification challenging ${ }^{11}$. Unlike the other irAEs, endocrine toxicities are typically irreversible; however, they are easily treated with hormone replacement and rarely require high-dose corticosteroids or treatment discontinuation. Short-term high-dose corticosteroids are required only for symptomatic hypophysitis (headache, vision changes), adrenal crisis, or severe thyrotoxicosis (for example, thyroid storm $)^{9,30}$. Consultation with an 
endocrinologist for any grade 2 or greater endocrine toxicity is recommended because of disease complexity and possible lifelong need for hormone replacement ${ }^{5,30}$.

\section{Respiratory}

Pneumonitis occurs predominantly in patients receiving PD-1/PD-L1 monotherapy or combination ICIs ${ }^{5,9,31}$. The pneumonitis incidence is low, but brings a high risk of poor clinical outcome if not treated early ${ }^{9,31}$.

Systematic reviews indicate that the incidence of pneumonitis is higher in patients with non-small-cell lung cancer and metastatic renal cell carcinoma than in those with melanoma ${ }^{13}$. The primary symptoms mimic other commonly encountered conditions in those populations and can include dyspnea and increased frequency of cough, with fever and chest pain occurring less frequently ${ }^{9,31}$. The pneumonitis diagnosis is confirmed radiographically and has a tendency to fall into 5 distinct radiographic subtypes ${ }^{5,31}$.

Treatment in the presence of incidental radiographic changes is controversial; most guidelines suggest delaying the ICI until radiographic improvement or resolution ${ }^{5,9,10}$. Compared with other iraEs, high-grade pneumonitis might require higher doses of corticosteroids (for example, 2-4 mg/ $\mathrm{kg}$ ) and empiric antibiotic treatment until infection is ruled out $^{5,9,10,31}$. Several immunosuppression approaches have been used in case reports for corticosteroid-refractory toxicity (for example, infliximab, cyclophosphamide, mycophenolate mofetil, intravenous immunoglobulin) ${ }^{9}$.

\section{Hepatic}

All ICIS can cause hepatic irAEs, with the frequency being significantly higher with combination $\mathrm{ICIs}^{5,9}$.

The clinical presentation is typically asymptomatic, with elevations in liver enzymes that rarely progress to clinical hepatitis ${ }^{5,9,10,11}$. Elevations in liver enzymes warrant more frequent monitoring until a downward trend is documented ${ }^{10}$. Other causes, such as disease progression, drug-induced hepatotoxicity, alcohol intake, or viral infection, should be ruled out before treatment is initiated ${ }^{5,10,11 \text {, }}$. In the case of corticosteroid-refractory hepatitis, mycophenolate mofetil is the preferred immunosuppressant because of the risk of additive hepatotoxicity with infliximab ${ }^{10,11}$.

\section{SUMMARY}

In this new age of cancer treatment using ICIs, an understanding of toxicity patterns and of the assessment and management of irAEs is an essential skill for general practitioners in oncology. Collaborative experience -sharing by clinicians and further research will be critical in identifying patients at higher risk of irAes so as to optimize monitoring, guide treatment, and extend the duration of ICI therapy to improve cancer outcomes.

\section{Key Points}

Any organ system in the body can be affected by iraEs, with dermatologic, gastrointestinal, endocrine, respiratory, and hepatic effects being the most commonly reported in clinical trials.

Toxicity patterns, pharmacokinetics, and dose-toxicity relationships are different for CTLA- 4 inhibitors and
PD-1/PD-L1 inhibitors because of their distinct mechanisms of action. Colitis, rash, hypophysitis, and pruritus occur more frequently with cTLA-4 inhibitors; pneumonitis, dysthyroidism, arthralgia, myalgia, and vitiligo are more frequent with the PD-1/PD-L1 inhibitors.

Thorough and individualized patient education, followup, and assessment are key to early identification and management of irAEs.

Any new symptoms that appear while a patient is taking ICIs should be investigated; the differential includes disease progression, fortuitous events related to the cancer or previous medical conditions, and irAEs. Treatment of iraes involves mainly supportive care, early management with corticosteroids, and addition of alternative immunosuppression (infliximab) for toxicity refractory to corticosteroids.

\section{CONFLICT OF INTEREST DISCLOSURES}

I have read and understood Current Oncology's policy on disclosing conflicts of interest, and I declare the following interests: I have received honoraria from Amgen, AstraZeneca, Bristol-Myers Squibb, CARE, Canadian Association of Pharmacists in Oncology, and Celgene. I have also received fees as an advisory board member from AbbVie, AstraZeneca, Celgene, Hoffman-La Roche, Pfizer, and Sanofi.

\section{AUTHOR AFFILIATIONS}

*Department of Pharmacy, Horizon Health Network-The Moncton Hospital, Moncton, NB, and Canadian Association of Pharmacy in Oncology, Vancouver, BC.

\section{REFERENCES}

1. Sweis RF, Luke JJ. Mechanistic and pharmacologic insights on immune checkpoint inhibitors. Pharmacol Res 2017;120:1-9.

2. Champiat S, Lambotte O, Barreau E, et al. Management of immune checkpoint blockade dysimmune toxicities: a collaborative position paper. Ann Oncol 2016;27:559-74.

3. Gong J, Chehrazi-Raffle A, Reddi S, Salgia R. Development of PD-1 and PD-L1 inhibitors as a form of cancer immunotherapy: a comprehensive review of registration trials and future considerations. J Immunother Cancer 2018;6:8-25.

4. Alsaab HO, Sau S, Alzhrani R, et al. PD-1 and PD-L1 checkpoint signaling inhibition for cancer immunotherapy: mechanism, combinations, and clinical outcome. Front Pharmacol 2017;8:561.

5. Puzanov I, Diab A, Abdallah K, et al. on behalf of the Society for Immunotherapy of Cancer Toxicity Management Working Group. Managing toxicities associated with immune checkpoint inhibitors: consensus recommendations from the Society for Immunotherapy of Cancer (sITC) Toxicity Management Working Group. J Immunother Cancer 2017;5:95.

6. Papaioannou NE, Beniata OV, Vitsos P, Tsitsilonis O, Samara P. Harnessing the immune system to improve cancer therapy. Ann Transl Med 2016;4:261.

7. Postow MA, Sidlow R, Hellmann MD. Immune-related adverse events associated with immune checkpoint blockade. NEngl J Med 2018;378:158-68.

8. Day D, Hansen AR. Immune-related adverse events associated with immune checkpoint inhibitors. BioDrugs 2016;30:571-84.

9. BrahmerJR,LacchettiC,SchneiderBJ,etal. on behalfoftheNational Comprehensive Cancer Network. Management of immunerelated adverse events in patients treated with immune checkpoint inhibitor therapy:American Society of Clinical Oncology clinical practice guideline. J Clin Oncol 2018;36:1714-68. 
10. Haanen JBAG, Carbonnel F, Robert C, et al. on behalf of the esmo Guidelines Committee. Management of toxicities from immunotherapy: Esmo clinical practice guidelines for diagnosis, treatment and follow up. Ann Oncol 2017;28(suppl 4):iv119-42.

11. Sosa A, Cadena EL, Olive CS, Karachaliou N, Rosell R. Clinical assessment of immune-related adverse events. Ther Adv Med Oncol 2018;10:1758835918764628.

12. Cappelli LC, Gutierrez AK, Bingham CO 3rd, Shah AA. Rheumatic and musculoskeletal immune-related adverse events due to immune checkpoint inhibitors: a systematic review of the literature. Arthritis Care Res (Hoboken) 2017;69:1751-63.

13. Khoja L, Day D, Wei-Wu Chen T, Siu LL, Hansen AR. Tumourand class-specific patterns of immune-related adverse events of immune checkpoint inhibitors: a systematic review. Ann Oncol 2017;28:2377-85.

14. Kumar V, Chaudhary N, Garg M, Floudas CS, Soni P, Chandra AB. Current diagnosis and management of immune related adverse events (irAEs) induced by immune checkpoint inhibitor therapy. Front Pharmacol 2017;8:49. [Erratum in: Front Pharmacol 2017;8:311]

15. Johnson DB, Beckermann KE, Wang DY. Immune checkpoint inhibitor therapy in patients with autoimmune disease. Oncology (Williston Park) 2018;32:190-4.

16. Leonardi GC, Gainor JF, Altan M, et al. Safety of programmed death-1 pathway inhibitors among patients with non-smallcell lung cancer and preexisting autoimmune disease. J Clin Oncol 2018;36:1905-12.

17. Abdel-Wahab N, Shah M, Lopez-Olivo MA, Suarez-Almazor ME. Use of immune checkpoint inhibitors in the treatment of patients with cancer and preexisting autoimmune disease. Ann Intern Med 2018;168:121-30.

18. Eigentler TK, Hassel JC, Berking C, et al. Diagnosis, monitoring, and management of immune-related adverse drug reactions of anti-PD-1 antibody therapy. Cancer Treat Rev 2016;45:7-18.

19. Davies M, Duffield EA. Safety of checkpoint inhibitors for cancer treatment: strategies for patient monitoring and management of immune-mediated adverse events. Immunotargets Ther 2017;6:51-71.

20. Bertrand A, Kostine M, Barnetche T, Truchetet ME, Schaeverbeke T. Immune related adverse events associated with
anti-CTLA- 4 antibodies: systematic review and meta-analysis. BMC Medicine 2015;13:211-21.

21. Naidoo J, Cappelli LC, Forde PM, et al. Inflammatory arthritis: a newly recognized adverse event of immune checkpoint blockade. Oncologist 2017;22:627-30.

22. Lin R, Yellin MJ, Lowy I, Safferman A, Chin K, Ibrahim R. An analysis of the effectiveness of specific guidelines for the management of ipilimumab-mediated diarrhea/ colitis: prevention of gastrointestinal perforation and/or colectomy [abstract 9063]. J Clin Oncol 2008;26(suppl 20):. [Available online at: http://ascopubs.org/doi/abs/10.1200/ jco.2008.26.15_suppl.9063; cited 7 September 2018]

23. Spain L, Diem S, Larkin J. Management of toxicities of immune checkpoint inhibitors. Cancer Treat Rev 2016;44:51-60.

24. Woodworth T, Furst DE, Alten R, et al. Standardizing assessment and reporting of adverse effects in rheumatology clinical trials II: the rheumatology common toxicity criteria v.2.0. J Rheumatol 2007;34:1401-14.

25. Baxi S, Yang A, Gennarelli RL, et al. Immune-related adverse events for anti-PD-1 and anti-PD-L1 drugs: systematic review and meta-analysis. BMJ 2018;360:k793.

26. Cancer Care Ontario (cco). Immune Checkpoint Inhibitor Toxicity: Clinical Practice Guideline. Toronto, ON: cco; 2018. [Downloadable from: https://www.cancercareontario.ca/ en/guidelines-advice/types-of-cancer/52976; cited 7 June 2018]

27. Sibaud V. Dermatologic reactions to immune checkpoint inhibitors: skin toxicities and immunotherapy. Am J Clin Dermatol 2018;19:345-61.

28. Prieux-Klotz C, Dior M, Damotte D, et al. Immune checkpoint inhibitor-induced colitis: diagnosis and management. Target Oncol 2017;12:301-8.

29. Sznol M, Postow MA, Davies MJ, et al. Endocrine-related adverse events associated with immune checkpoint blockade and expert insights on their management. Cancer Treat Rev 2017;58:70-6.

30. Illouz F, Briet C, Cloix L, et al. Endocrine toxicity of immune checkpoint inhibitors: essential crosstalk between endocrinologists and oncologists. Cancer Med 2017;6:1923-9.

31. Chuzi S, Tavora F, Cruz M, et al. Clinical features, diagnostic challenges, and management strategies in checkpoint inhibitor-related pneumonitis. Cancer Manag Res 2017;9:207-13. 